\title{
O ESPAÇO QUE SOMOS: AS RELAÇÕES ENTRE A FAVELA E A CONSTRUÇÃO DA SUBJETIVIDADE EM BECOS DA MEMÓRIA, DE CONCEIÇÃO EVARISTO
}

The space we are: the relationship between the favela space and the construction of subjectivity in Becos da memória by Conceição Evaristo

\author{
Ariane Avila Neto de Farias \\ https://orcid.org/0000-0002-9828-7980 \\ Lilian Greice dos Santos Ortiz da Silveira
}

https://orcid.org/0000-0001-7485-5587

Universidade Federal do Rio Grande, Programa de Pós-Graduação em Letras, Rio Grande,

RG, Brasil.96203-900 - ppgletras@furg.br

Resumo: O presente trabalho visa analisar aspectos referentes ao espaço na obra Becos da Memória (2017), da autora Conceição Evaristo. Entende-se aqui que a favela, lugar em que o romance é ambientado, ocupa papel de fundamental importância na construção de tal narrativa, agindo na representação das personagens negras na escrita de Evaristo. Esse espaço-favela é lugar tanto de pertencimento quanto de trânsito dos indivíduos, reforçando a ideia de que os espaços por onde os sujeitos passam são organizados tendo como base suas experiências e trocas com o seu corpo. Nesse sentido, ao dar voz ao "espaço-favela" faz-se o movimento de descentralização, retirando o véu que cobriu os sujeitos marginalizados, dando, assim, voz às diferenças. Tais reflexões serão realizadas a partir de apontamentos de importantes teóricos como Luis Alberto Brandão (2013) e Paul Ricoeur (2003) que pensam o espaço como elemento de uma história, fundamento de caráter inseparável ao indivíduo narrado.

Palavras-chave: Espaço. Literatura Brasileira. Favela. Conceição Evaristo.

Abstract: The present work aims to analyze aspects related to the space in Becos da Memória (2017), by the author Conceição Evaristo. It is understood here that the favela, place where the novel is set, occupies role of fundamental importance in the construction of such narrative, acting in the representation of the black personages in the writing of Evaristo. This favela space is a place of both belonging and transit of individuals, reinforcing the idea that the spaces where the subjects pass are organized based on their experiences and exchanges with their body. In this sense, giving voice to the "space-favela" is the movement of decentralization, removing the veil that covered marginalized subjects, thus giving voice to differences. Such reflections will be carried out from notes by important theorists such as Luis Alberto Brandão (2013) and

Esta obra está licenciada sob uma Creative Commons - Atribuição 4.0 
Paul Ricoeur (2003) who think of space as an element of a story, a foundation of character inseparable from the narrated individual.

Keywords: Space. Brazilian literature. Favela. Conceição Evaristo.

Pensar acerca do sujeito é refletir sobre os diversos aspectos que envolvem a formação de sua subjetividade. Gênero, classe social e raça bem como memórias, traumas e trajetórias são alguns dos elementos que constituem os diversos "eus" em toda a sua complexidade e individualidade. Fluidas e não mais fixas, observa-se cada vez mais o deslocamento das identidades. Nesse sentido, a partir do entendimento da multiplicidade de experiências e das inter-relações como fatores importantes para a compreensão do indivíduo, é que se faz fundamental olhar para os elementos externos que constroem os espaços por onde os sujeitos transitam. Atentar para este é perceber traços da formação de subjetividades mais plurais e, ao mesmo tempo, mais politizadas, sendo esse aspecto, assim, também categoria para a compreensão do mundo.

É no romantismo que as noções referentes ao espaço passam a ter destaque nos processos de análises das diferentes obras literárias. A vista do anteriormente mencionado, é relevante observar o afirmado por David Lodge (2011, p. 67) de que "[o romantismo] é o grande responsável pela ponderação dos "efeitos [do ambiente] sobre o homem", abrindo os olhos do mundo "para a beleza sublime das paisagens naturais [...]". Tomando essa afirmação como verdade, esse constitui-se, não apenas em seu sentido vinculado à paisagem ou ao retrato, mas como lugar de empoderamento e formação de subjetividade. É dessa maneira que se entende tal elemento "para além de sua vivência" (BRANDÃO, 2013, p. 05).

$\mathrm{Na}$ contemporaneidade, os estudos sobre o espaço ganham ainda destaque, demarcando profundamente sua função social, cultural e política ao se pensar acerca dos "eus" que a todo o momento se movem. Refletir acerca do espaço narrativo é também teorizar sobre as diferentes classes, etnias, gêneros e corpos, as diversas formas de demonstração de afeto bem como sobre o sentimento de pertencimento. O espaço geográfico é concebido como um produto social e histórico que possibilita a análise da realidade tanto em sua dimensão material quanto em sua representação. Destarte, é possível afirmar que o presente apresenta novas formas de mobilidades e muitas rupturas com a concebida moral social e, a geografia é um instrumento de análise que "faz projeções - imaginárias, cartográficas, militares, econômicas, históricas ou, em sentido geral, culturais. [Ela] possibilita a construção de vários tipos de conhecimento" (SAID, 1995, p. 118).

A concepção acima apresentada faz do espaço um aliado na representação de sujeitos até então marginalizados. Ao colocar vozes silenciadas em destaque, este reconfigura-se em direção à valorização de outras experiências, afinal de contas, como bem pontuado por Foucault, ao comentar o trabalho de Bachelard, "não vivemos num espaço homogêneo e vazio, mas, ao contrário, num espaço todo carregado de qualidades, um espaço que talvez seja povoado de fantasmas" (FOUCAULT, 2013, p. 13). É nesse sentido que se compreende que todos os lugares têm histórias para contar; assim como outros elementos, ele é um meio para se analisar os sujeitos, já que não há grupo nem gênero de atividade coletiva que não tenha alguma 
relação com o lugar [...]" (HALBWACHS, 2006, p. 170).

Pelo exposto, o presente artigo tem como o objeto analisar aspectos referentes a construção do espaço narrativo da obra Becos da memória (2017), da escritora mineira Conceição Evaristo. Neste trabalho buscar-se-á refletir acerca dos entrecruzamentos entre as personagens periféricas apresentadas por Evaristo e espaço-favela. Salienta-se a compreensão do espaço contemporâneo como aquele disposto ao movimento, à mobilidade, e que, consequentemente, conduz a uma reflexão sobre os corpos e mentes que por ele transitam. É também importante salientar que tal análise compreende o espaço como subjetivo, imaginário e fruto da ficcionalidade. Essa reflexão toma como fundamentação teórica, trabalhos como os de Paul Ricouer (2007), Maurice Halbwachs (2006) e Luis Alberto Brandão (2013).

Becos da Memória (2017) foi o segundo romance a ser publicado da escritora mineira, Conceição Evaristo, que aparece no cenário da literatura brasileira com a publicação de poemas no Cadernos Negros ainda na década de 1990, e que desde sua primeira narrativa trabalha com o objetivo de dar voz aos subalternos, direcionando o seu olhar aos "invisíveis". Sua escrita vai ser marcada pela abordagem de temáticas delicadas para a literatura como as questões referentes a gênero e raça.

A obra aqui analisada foi escrita no período entre o final da década de 1970 e início da de 1980, ficando em engavetado por longos 20 anos, o que acaba revelando a existência de obstáculos dentro do âmbito literário para publicação da obra que não apenas retrata sujeitos marginalizados, mas foi escrita por alguém que vem das margens. $\mathrm{O}$ romance vai narrar, no transcorrer de suas páginas, a história de diversos personagens moradores de uma favela que está em processo de desfavelamento, que está sendo destruída para dar lugar a uma construção de "homens ricos". As vozes de Maria Velha, Vó Rita, Negro Alírio, Bondade, Ditinha, Balbina, Filó Gazogênia, Cidinha-Cidoca, Tio Totó e Negra Tuína são as de sujeitos que, como a primeira narrativa de Evaristo, ocupam os espaços das margens; aqueles que como nas palavras de Maria-Nova, a menina que dará voz indivíduos na narrativa, são “os oprimidos, os miseráveis; em todas histórias, quase nunca eram os vencedores, e sim, quase sempre, os vencidos" (EVARISTO, 2017, p. 63).

É através de uma narrativa fragmentada que se tem acesso às lembranças da época em que a favela foi construída; um passado repleto de esperança e desejos de um lugar que aos poucos vai sendo de todo daquelas pessoas que ali chegaram. Pequenos relatos de homens, mulheres, crianças que provam a força dos fragmentos sobre a totalidade e que criam um espaço, que através do tempo, é construído pelos sujeitos; diferentes “eus” que vão também sendo constituídos por esse elemento. Partes que representam narrativas que se completam e que se confundem. Mas, que no presente, lhes está sendo tomado em benefício daqueles que fazem parte de uma esfera formada por aqueles de maior poder aquisitivo. Maria-Nova relata a tristeza e o desespero da comunidade ao ver o seu único lugar seguro sendo desmantelado, junto a certeza de que mais uma vez esses sujeitos serão apagados, silenciados frente às injustiças sociais. 
Os tratores da firma construtora estavam cavando, arando a ponta norte da favela. Ali, a poeira se tornava maior e as angústias também. Algumas famílias já estavam com ordem de saída e isto precipitava a dor de todos nós. Cada família que saia, era uma confirmação de que chegaria a nossa vez. Ofereciam duas opções ao morador: um pouco de material, tábuas e alguns tijolos para que ele construísse outro barracão, num lugar qualquer, ou uma indenização simbólica, um pouco de dinheiro. [...] Depois vinha o pior, decorrido o prazo de permanência, nem o dinheiro, nem as tábuas, nem os tijolos, só o nada (EVARISTO, 2017, p. 71).

O excerto acima apresentado descreve o grande descaso sofrido pelos sujeitos que na favela habitam. Os responsáveis pelo desmonte daquele espaço, em oposição ao sofrimento dos moradores daquela comunidade, não demonstram preocupação com o futuro dessas pessoas. Para esses, os grandes empresários, a favela está sendo destruída para um bem maior; para o atendimento do crescimento e das necessidades de uma sociedade que preza por um sistema financeiro, gerador de poder, ao mesmo tempo em que esquece os seus iguais. É em um contexto no qual poucos materiais de construção ou um baixo valor em dinheiro são compreendidos como instrumentos suficientes para a compensação do fato de seres humanos estarem sendo retirados de suas casas, e porque não dizer, de suas histórias, que os sujeitos vão perdendo também a sua identidade. Identidade essa que foi e é concebida pelo e a partir do espaço-favela; uma narrativa que todos contribuíram para a construção.

É interessante salientar que a obra de Evaristo (2017) vai ao encontro do defendido por Halbwachs (2006) de que o espaço representa um papel fundamental na memória coletiva. Aquele espaço é construído principalmente pela perspectiva daqueles que ali estão, "porque todas as partes do espaço que ele ocupou correspondem a outros tantos aspectos diferentes da estrutura e da vida de sua sociedade, pelo menos o que nela havia de mais estável" (HALBWACHS, 2006, p. 159-160). A fala do personagem Totó demonstra o afirmado:

- Maria-velha, dizem uns que a vida é um perde e ganha. Eu digo que a vida é uma perdedeira só, tamanho é o perder. Perdi Miquilina e Catita. Perdi pai e mãe que nunca tive direito, dado o trabalho de escravo nos campos. Perdi um lugar, uma terra, que pais de meus pais diziam que era um lugar grande, de mato, bichos. De gente livre e sol forte... E hoje, agora a gente perde um lugar de que eu já pensava dono. Perder a favela! Bom que meu corpo está pedindo terra. Não vou mesmo muito além. Se eu estivesse mais moço, começava em qualquer lugar novamente. Comecei cheio de dor, mas comecei outra vida quando cheguei são, salvo e sozinho na outra banda do rio. O tempo foi passando, pensava que estava ganhando alguma coisa. Nada, só dor. A dor sempre bate no coração da gente. Cada dor cai como uma pedra no peito. Pedras pontiagudas, e foram tantas! A dor dói fina, firme. Tantas pedradas. Tantas! E mais aquela quando Nega Tuína morreu. (EVARISTO, 2017, p. 29)

Totó em sua fala sugere a íntima relação entre o espaço-favela e os sujeitos, já que a narração acerca do primeiro acaba por evocar aspectos da formação das identidades daqueles indivíduos. Percebemos a forte ligação com o espaço a partir da expressão da tristeza em ter que deixar um lugar de que já se considerava dono. As memórias que surgem no momento em que Totó está relembrando seu passado o colocam como um sujeito que sofreu muitas perdas 
ao longo se sua vida e que não se conforma em ter que deixar seu local de pertencimento.

Não só Totó sofre com uma dor constante devido a tantas perdas e lutas, mas também todos os personagens da narrativa que têm suas vidas permeadas pelo sofrimento por estarem inseridos em um espaço à margem da sociedade e sofrer um processo de silenciamento. A dor em ter que deixar um espaço que constituía a todos não é apenas de Totó, mas de todos os moradores da favela que se veem obrigados a partir e deixar para trás toda a história ali construída ao longo de suas vidas. O espaço-favela é onde estão suas mais variadas memórias individuais e coletivas; onde nosso pensamento se fixa para que essa ou aquela categoria de lembrança apareça, e nossa imaginação seja capaz de reconstruir o passado (HALBWACHS, 2006, p. 170).

Assim, os fragmentos de histórias vão apresentar os diversos vínculos que foram formados entre sujeitos, memória e aquele espaço. Relações que foram construídas a partir do momento em que aquele lugar começa a ser construído e entendido como lar por aqueles que ali primeiro chegaram, como Totó e Nega Tuína que tem suas histórias narradas por MariaNova desde o momento em que chegaram na cidade, que em todas as suas expectativas acreditavam em um futuro melhor no lugar em que acabavam de chegar como narrado por Tio Totó:

[...] Vinha sabendo onde iria ficar. Um amigo estava esperando por eles. Tinha dinheiro suficiente que dava para comprar um barraco. [...] Aqui na capital carece da gente aprender um modo novo de viver... Quando cheguei na favela, ainda tinha muito lugar vazio. Essa minha casa era só um quartinho, fui aumentando aos poucos. Hoje você vê, menina, são quatro cômodos; comecei com Nega Tuína (EVARISTO, 2017, p. 89).

A passagem apresentada sugere o papel social significativo que Maria-Nova empenhará, nesse momento de destruição, ao narrar as histórias as vidas de pessoas simples que em seu discurso externam o cuidado, a crença de um mundo melhor e uma preocupação constante com o outro. As vozes de todos que ali vivem ecoam na menina que percebe que a sua narração irá perpetuar as histórias daquele lugar; um espaço que logo será esquecido tendo em vista que os que ali moram em nada interessam para a cidade que cresce. São as histórias como a de Tio Totó, um dos primeiros a chegar ao local, que Maria-Nova precisa conservar para lembrar àqueles que naquele espaço não mais estarão, e seus descendentes, sobre as suas origens.

Dessa maneira, ao dar voz aos que vivem ali, Maria-Nova descreve uma história de permutação entre espaço e sujeitos, uma narrativa de trocas, de reconhecimento e de pertencimento. Nas histórias expostas, a narradora vai ao encontro do afirmado por Santos: “o espaço deve ser considerado com um conjunto indissociável de que participam, de um lado, certo arranjo de objetos geográficos, objetos naturais e objetos sociais, e, de outro, a vida que os preenche e os anima, seja a sociedade em movimento" (SANTOS, 1986, p. 10). O trecho a seguir mostra a preocupação de Maria-Nova em manter viva uma memória coletiva a partir da recordação do espaço e das pessoas que nele viviam, revelando a impossível dissociação entre espaço e indivíduos: 
Hoje a recordação daquele mundo me traz lágrimas aos olhos. Como éramos pobres! Miseráveis talvez! Como a vida acontecia simples e como tudo é complicado! [...] Escrevo como uma homenagem póstuma à Vó Rita, que dormia embolada com ela, a ela que nunca consegui ver plenamente, aos bêbados, às putas, aos malandros, às crianças vadias que habitam os becos de minha memória. Homenagem póstuma às lavadeiras que madrugavam os varais com roupas ao sol. Às pernas cansadas, suadas, negras, aloiradas de poeira do campo aberto onde aconteciam os festivais de bola da favela. Homenagem póstuma ao Bondade, ao Tião Puxa-Faca, à velha Isolina, à D. Maria, mãe do Aníbal, ao Catarino, à velha Lia, à Terezinha da Oscarlinda, à Mariinha, à Donana do Padin. Homens, mulheres, crianças que se amontoaram dentro de mim, como amontoados eram os barracos de minha favela. (EVARISTO, 2017, p. 17)

Maria-Nova revela na passagem acima como sua formação identitária está intimamente relacionada não apenas com o espaço em que cresceu, mas também com todas as pessoas com as quais conviveu e que contribuíram para a existência de uma memória coletiva dos que viveram na favela em barracos amontoados inseridos em um ambiente de extrema pobreza, isolado dos centros econômicos e de poder. Nessa perspectiva, o espaço narrado vai evidenciar o total apagamento de indivíduos marginalizados e esquecidos, que podem ser "jogados" de um lado para outro quando da conveniência daqueles que ocupam lugares sociais privilegiados. Ao se pensar nos problemas enfrentados na favela narrada, que nas palavras de um dos personagens apresentada por Maria-Nova é "grande como uma cidade" (EVARISTO, 2017, p. 24), é também refletir acerca dos problemas que batem às portas das mais variadas cidades brasileiras.

Afirma Michel Foucault (1984, p. 252) que, “o espaço é fundamental em qualquer forma de vida comunitária", apontando que ele é importante para se refletir sobre a constituição de regras, limites e parâmetros para o conviver em sociedade; os espaços por onde os sujeitos passam são organizados tendo como base suas experiências e trocas com o seu corpo, bem como com outras pessoas com a intenção de conformá-los as suas necessidades biológicas e sociais. O espaço para Foucault também é elemento de demarcação dos jogos de poder que gerem o social; é desse modo que a favela vai trabalhar, na escrita de Evaristo, como o retrato daqueles sujeitos marginalizados; indivíduos sem voz e força diante de um jogo dos dominantes. $\mathrm{O}$ desmonte deste representa ainda o esfacelamento e a dor das pessoas moradoras dos diversos barracos que a constituem; a confirmação do não pertencimento daqueles que vivem à margem aos movimentos do desenvolvimento do capitalismo. Esses não são considerados protagonistas desse crescimento, mas mão-de-obra barata para o progresso desse poder.

Os desastres vividos por cada um em nada se comparam ao momento que vivem: a perda coletiva do lugar para o qual voltam todos os dias após a luta diária diante de uma sociedade desigual. O apagamento de tal espaço demarca, dessa forma, o domínio da objetividade moderna, em detrimento das manifestações de afeto e solidariedade que esse é palco. Perder a favela é perder um pedaço do que são; não ter mais aqueles que se ama por perto, afastar-se daquilo que ajudaram a construir e que os ajudou em sua construção. Eles estavam perdendo um espaço que há tanto tempo era deles, vendo que "Mais e mais famílias estavam indo embora." (EVARISTO, 2017, p. 87) e se questionando: "E quando chegasse a vez da família 
dele? O que seria de todos?” (EVARISTO, 2017, p. 87). As palavras de Tio Totó confirmam a dificuldade que é imaginar um tempo sem o espaço que eles chamam de lar, importante e fundamental para a constituição do seus "eus": "todos sabiam que a favela não era o paraíso, mas ninguém queria sair. Ali perto estava o trabalho, a sobrevivência de todos. [...] Aqueles tratores trariam tanta tristeza, trariam desgraça até" (EVARISTO, 2017, p. 72).

O teórico Paul Ricouer (2007), ao discorrer sobre questões acerca da constituição da memória, aponta para a relação significativa construída entre os sujeitos e os espaços que ele habita. A partir dos apontamentos do estudioso francês, compreende-se que os diferentes laços criados por esse encontro colocam o segundo em um lugar tão importante quanto os demais elementos narratológicos, já que ele é um dos principais meios de reflexão das qualidades, sentidos e lembranças do primeiro tanto em sua individualidade quanto na sua coletividade. $\mathrm{O}$ pesquisador afirma,

as lembranças de ter morado [...] em tal cidade ou de ter viajado a tal parte do mundo são particularmente eloquentes e preciosas, elas tecem ao mesmo tempo uma memória íntima e uma memória coletiva [...] nessa lembranças tipo, o espaço corporal é de imediato vinculado ao espaço do ambiente (RICOUER, 2007, p. 157).

O excerto acima reforça a indissociabilidade entre sujeitos e os espaços a que esses fazem parte; há a impossibilidade da desvinculação entre espaço e corpo, ao sublinhar o vínculo do segundo à percepção e à esfera do sensível (BRANDÃO, 2013, p. 57). Verifica-se, dessa forma, que o olhar espacial supõe olhar a realidade sociocultural em um exercício de verificar as marcas dos mais variados dispositivos inscritos nesse espaço, sugerindo o assinalado por Callai (2009, p. 234-235) de que é no "[...] cotidiano da própria vivência que as coisas vão acontecendo e, assim, configurando o espaço, dando feição ao lugar".

Nesse mesmo sentido, pontua Callai (2009) que espaço construído é resultado da história das pessoas, dos grupos que nela vivem, como trabalham, se alimentam e usufruem do lazer. Isto resgata a identidade, e neste processo, é muito importante reconhecer os vínculos afetivos que ligam as pessoas aos lugares. Esses vínculos, para Ricoeur (2007), acabam influenciando na constituição de uma memória e consciência coletiva. O pertencimento a um espaço e a um grupo faz com que os sujeitos definam suas identidades a partir de experiências que são compartilhadas. Dessa forma, os moradores da favela desmantelada, na narrativa de Evaristo, constituíam-se em "gerações inteiras [que] nasciam e cumpriam tempo de vida acostumados à miséria, fazendo muitas das misérias razão da vida" (EVARISTO, 2017, p. 141) e, assim, são eles as memórias e as histórias - mortes, nascimentos, brigas, amigos, choros e sorrisos - desse lugar que será apagado, evidenciando o desprezo social por quem ali mora.

$\mathrm{O}$ espaço urbano, no auge de seu desenvolvimento, diferente daquele micro espaço configurado pela favela, rejeita os indivíduos que para ele não estão suficientemente preparados para a vida da atualidade, e toda a rapidez e avanços que a acompanham. Ao apagar o espaço da margem, o centro confirma que os sujeitos marginalizados não possuem vidas verdadeiramente suas, mas sim vidas que não dependem de suas vontades. Nessas relações de 
poder, os barracos e seus moradores, em nenhum aspecto, ganham. Os grupos do centro acabam normalmente sendo os que vencem, realidade comum e que faz parte da história dos indivíduos das margens; situação que acaba sendo repetida de geração em geração como Evaristo (2017) retrata no trecho em que mostra Maria-Nova e suas conclusões sobre o espaço em que vive bem como sobre os sujeitos que convive:

Mas a menina é do tipo que gosta de pôr o dedo na ferida, não na ferida alheia,
mas naquela que ela traz no peito. Na ferida que ela herdou de Mãe Joana, de
Maria-Velha, de Tio Totó, do louco Luisão da Serra, da avó mansa, que tinha
todo o lado direito do corpo esquecido, do bisavô que tinha visto os sinhôs
venderem Ayaba, a rainha. Maria-Nova, talvez, tivesse o banzo no peito.
Saudades de um tempo, de um lugar, de uma vida que ela nunca vivera.
Entretanto o que doía mesmo em Maria-Nova era ver que tudo se repetia, um
pouco diferente, mas, no fundo, a miséria era a mesma. O seu povo, os
oprimidos, os miseráveis; em todas as histórias, quase nunca eram os
vencedores, e sim, quase sempre os vencidos. A ferida dos do lado de cá
sempre ardia, doía e sangrava muito (EVARISTO, 2017, p. 63).

O trecho acima sugere uma história que identifica os sujeitos marginalizados como os que carregam consigo marcas de um passado doloroso que sempre deixou evidente o apagamento a que esses foram submetidos. Entretanto, tanto sofrimento parece estar longe de acabar e se intensifica com o processo de desfavelamento que pretende retirar os indivíduos das margens de um espaço que sempre identificaram como seu e o que acabava os definindo. A desconstrução desse espaço, na qual pessoas esmorecem e, até mesmo, morrem, acentua a ideia de que se refletir acerca desse e sua composição à subjetividade é destacar uma sociedade hierarquizada entre os sujeitos. Os moradores da favela têm ainda mais certeza que certas vidas valem mais do que outras.

A possibilidade de alegrias, a inocência dos que moram no espaço que se apaga, e mesmo a certeza de que nada irá mudar o seu destino, faz com que os moradores utilizem as próprias máquinas, deixadas no lugar dos barracos já destruídos, como forma de divertimento. Nenhum tipo de cuidado é tomado pela empresa responsável pelo processo de desfavelamento, que não pesa os perigos que todos correm, deixando-os à mercê de constantes riscos; as máquinas ficam expostas pelo lugar, marcando o total descaso para com essas pessoas. $\mathrm{O}$ trágico mais de uma vez acontece, evidenciando a morte já anunciada pela pobreza: a primeira delas com os "homens-vadios-meninos", que durante a noite, após muito beberem, enxergam naqueles equipamentos a possibilidade de aproveitar "prazer que não tiveram na infância", (EVARISTO, 2017, p. 74), que acaba os levando a morte; e, a segunda, com o menino Brandino, situação narrada por Maria-Nova que afirma que a tragédia causada ao jovem se tornou o ganha pão de sua família:

Foi isso que aconteceu. Brandino vinha viando, leve, voando como uma pluma. O trator ali parado, pesadão. O rosto, o corpo, o menino frágil. Não a morte instantânea, rápida, como havia acontecido com os homens-vadiosmeninos, não houve. Brandino foi para o hospital, ficou meses. Voltou sim, calado, morto-vivo, bobo, alheio, paralíticos. A mãe pegava o menino, 
colocava num carrinho de madeira, pegava os três menores e saía a pedirganhar esmolas (EVARISTO, 2017, p. 80).

Os desfortúnios narrados marcam a fragilidade daqueles que moram na favela diante da grandiosidade da empresa que deles toma o espaço. Uma violência extrema que sinaliza o fim da favela e demarca um "caminho marcado pela observação das mazelas de um projeto urbano que não consegue solucionar a demanda dos excluídos" (FONSECA, 2017, p. 192) e que em suas atitudes busca mostrar um poder sempre maior que o dos moradores da favela como sugere a situação resposta ao motim exigindo a retirada dos tratores organizado por Negro Alírio após o acidente de Brandino, "[...] novos tratores chegaram. Chegaram bravios, recomeçando o trabalho. Só se ouvia barulho e sentia poeira. O desfavelamento recomeçava" (EVARISTO, 2017, p. 81).

Evaristo, dessa maneira, apresenta a favela como um importante elemento para a construção das memórias dos sujeitos que ali moram. Este espaço representa as mais diferentes lembranças de alegrias e de medos, demonstrando a intrínseca relação entre esses dois elementos apontada por Bachelard (2008) ao afirmar que "a memória - coisa estranha! - não registra a duração concreta [...]. É pelo espaço, é no espaço que encontramos os belos fósseis de duração concretizados por longas permanências. O inconsciente permanece nos locais" (BACHELARD, 2008, p. 28-29). Todas as lembranças narradas pelas personagens estabelecem uma relação íntima com o espaço-favela e também mostram que, apesar de tantas dificuldades, os moradores ainda eram capazes de encontrar momentos de alegria:

Além dos festivais de bola, um ou outro momento em que a favela respirava alegria era nas festas juninas. Numa casa ou noutra, se acendia uma fogueira. Colhia-se dinheiro de quem pudesse dar, comprava-se canjica e seus ingredientes, e estava tudo pronto para um encontro, para uma festa. Se viesse alguém que não tivesse participado com dinheiro, nunca lhe seria negado um prato. (EVARISTO, 2017, p. 43)

Os poucos momentos de alegria evidenciavam a união de quem vivia na favela e o espírito de solidariedade de um povo humilde, mas que era capaz de compartilhar o pouco que tinha para que existissem momentos de felicidade. No entanto, até mesmo esses momentos eram usados para fortalecer a disparidade entre o povo da favela e o restante. Quando se fala sobre uma festa junina grandiosa na favela, o leitor fica sabendo que essa festa é realizada graças a Cabo Armindo que:

[...] morava numa área privilegiada da favela. Sua casa ficava no centro de um terreno enorme. Armava-se a fogueira, dançava-se a quadrilha. Os assistentes ficavam no terreiro ou do lado de fora da cerca de arame, que ladeava o terreno da casa dele. A casa era abaixo do nível da rua (do beco), de modo que as pessoas cá de cima assistiam a tudo também. Ele bancava toda a festa. Serviam-se canjica, doces, biscoitos, fogueira, batata-doce, quentão, tudo à vontade. Ninguém pagava nada. Diziam que ele apenas organizava a festa e cedia o local, mas quem bancava tudo eram os ricos que moravam no bairro nobre bem ao lado da favela. Bancavam para que os favelados não os importunassem. Havia outros bairros perto de favelas que as casas eram 
constantemente arrombadas. Parece que havia mesmo um acordo tácito entre os favelados e seus vizinhos ricos. Vocês banquem a nossa festa junina, deemnos as sobras de suas riquezas, oportunidades de trabalho para nossas mulheres e filhas e, antes de tudo, deem-nos água, quando faltar aqui na favela. Respeitem nosso local, nunca venham com plano de desfavelamento, que nós também não arrombaremos a casa de vocês. Assim, a vida seguia aparentemente tranquila. E dois grupos tão diversos teciam, desta forma, uma política da boa vizinhança (EVARISTO, 2017, p. 46-47, grifo da autora).

Fica evidente a disparidade entre os moradores da favela e os moradores do bairro vizinho considerado nobre. Verificamos a tentativa de exclusão e afastamento dos sujeitos marginalizados que deveriam se contentar com as sobras que lhes eram oferecidas e aceitar sua condição de subalternos. Ainda assim, eles acabam passando pelo processo de desfavelamento e tendo que se sujeitar as vontades do grupo dominante que não se importava com os favelados, nem com a história construída por eles naquele espaço. Com o desfavelamento eles seriam vítimas novamente de silenciamento e exclusão. Ao acabar com a favela, o grupo dominante estaria também acabando com as memórias construídas naquele ambiente.

Entretanto, é nesse cenário de perdas que Maria-Nova reconhece a força da escrita como importante instrumento de preservação das memórias do espaço-favela e dos sujeitos-favelados. A escrita funciona como uma possibilidade de registro de uma realidade difícil, mas que precisa ser narrada para que se transforme em uma forma de denúncia da árdua realidade enfrentada por quem está nas margens. É preciso dar voz aos invisíveis e retratar as memórias de uma coletividade que compartilha as mesmas lutas e anseios:

Sim, ela iria adiante. Um dia, agora ela já sabia qual seria a sua ferramenta, a escrita. Um dia, ela haveria de narrar, de fazer soar, de soltar as vozes, os murmúrios, os silêncios, o grito abafado que existira, que era de cada um e de todos. Maria-Nova escreveria a fala de seu povo (EVARISTO, 2017, p. 177).

Logo, Maria-Nova percebe na escrita uma forma de expor a fala de um grupo que foi constituída a partir de um lugar de exclusão. Sua linguagem e escrita em pedaços revela muito sobre a sensação de pertencimento àquele espaço, bem como acerca das trocas ocorridas entre os sujeitos da favela e o local que eles reconhecem como sendo pertencentes. Nesse sentido, é fundamental que a história construída por esse povo seja contada a partir de um olhar que realmente os compreenda e seja capaz de expressar a complexidade das relações ali estabelecidas.

Em Becos da Memória, a discussão sobre a relevância da escrita acaba por evidenciar que tradicionalmente temos acesso a um olhar expresso pelo centro, um olhar que não é capaz de exprimir a verdadeira realidade dos que não fazem parte do grupo que detém o poder. Nesse sentido, sobre o potencial da escrita de Maria-Nova, afirma Simone Schmidt (2017, p. 186), que "dar corpo à memória dos moradores da favela, caminhando em memória em sentido contrário ao dos estereótipos que se colam à pele dos subalternos em nossa sociedade, é, portanto, uma estratégia de grande impacto político e cultural". É isso que acontece quando Maria-Nova, na aula sobre história e libertação dos escravos, percebe que teria tanto para falar 
sobre escravos e libertação que "[...] teria para contar muitas vidas." (EVARISTO, 2017, p. 150), mas seria uma história diferente da de sua professora, pois para ela era preciso contar sobre "[...] uma senzala de que, hoje, seus moradores não estavam libertos, pois não tinham nenhuma condição de vida." (EVARISTO, 2017, p. 150). É revelada, então, a necessidade de se contar/escrever uma história que reflita acerca das condições de vida desses sujeitos. Assim, há, além da tentativa de resgatar as particularidades históricas, a personagem traz à tona também a memória coletiva. Toda a memória de um povo a partir de sua narrativa de luta e libertação:

Era uma História muito grande! Uma História viva que nascia das pessoas, do hoje, do agora. Era diferente de ler aquele texto. Assentou-se e, pela primeira vez, veio-lhe um pensamento: quem sabe escreveria esta história um dia? Quem sabe passaria para o papel o que estava escrito, cravado e gravado no seu corpo, na sua alma, na sua mente (EVARISTO, 2017, p. 150-151).

Assim, Maria-Nova não estaria contando uma história qualquer, mas sim uma narrativa que estava gravada no seu corpo e alma, uma vez que fazia parte do passado de seu povo. Uma história que tinha sido construída dentro de espaços específicos e que agora tinha continuidade dentro da favela. Todavia, o fato de estar sendo obrigada, junto com sua família e amigos, a deixar esse espaço, faz com que aflore o sentimento de perda de identidade e de sensação de pertencimento. Discutir memória é também discutir os espaços que permeiam a constituição dos sujeitos.

É no processo de escrita que Maria-Nova encontra uma forma de narrar a história de um "espaço social que não conhece as grandes avenidas, as ruas abertas em obediência a um plano arquitetônico" (FONSECA, 2017, p. 196), e que, ao mesmo tempo, visa transformar isso em uma tentativa de preservar uma memória que é de seus antepassados, sua e das gerações que ainda virão. Seria a partir dessa escrita que ela conseguiria revelar um olhar sobre o passado de sua gente, que a constitui enquanto sujeito.

Ademais, a escrita das breves histórias por Maria-Nova traça a estrutura sinuosa e multifacetada de um espaço que pode ser compreendido para além de seu papel de suporte aos sujeitos da narrativa (palco), protagonizando a função de veículo (ator) de um processo que está em constante movimento de lutas entre o já existente e o que impõe sua existência; o espaço é então participante ativo na narrativa, fazendo-se componente relevante de análise. Entende-se que esse propicia um conjunto de atuações para a consolidação das relações que se estabelecem entre os sujeitos que ali vivem, representado por suas histórias.

Nesse viés, ao escrever a favela - memórias e sujeitos -, Maria-Nova a configura como um lugar que carrega a intensa dramaticidade e constante busca pela razão da existência, em que a narrativa se passa entrecruza-se aos indivíduos que nele residem. Ao colocar esse espaço no centro de sua literatura, Evaristo (2017) evidencia a importância de se olhar para aqueles que há tanto são esquecidos e abandonados por centro detentor de poder; por um centro que os limita.

Por fim, percebe-se a valorização do espaço-favela como um elemento que organiza a sua narrativa, colocando em evidência os que vivem nele formando uma estrutura que não se 
dissolve, mas que se completa. O espaço-favela elaborado por Evaristo (2017) não só diz sobre suas especificidades, mas é uma marca de sua elaboração literária, ao mostrar-se constituído por um campo de (re)combinações de significados bem como subjetividades.

\section{Referências}

BACHELARD, Gaston. A poética do espaço. Trad. de Antonio de Pádua Danesi. 2. ed. São Paulo: Martins Fontes, 2008.

BRANDÃO, Luis Alberto. Teorias do espaço literário. Belo Horizonte: Perspectiva, 2013.

CALLAI, Copetti Helena. Estudar o lugar para compreender o mundo. In: CASTROGIOVANI, Antônio Carlos (Org.). Ensino de Geografia: práticas e textualizações no cotidiano. 7. ed. Porto Alegre: Mediação, 2009. p. 83-134.

EVARISTO, Conceição. Becos da memória. Rio de Janeiro: Pallas, 2017.

FONSECA, Maria Nazareth Soares. Posfácio: costurando uma colcha de memória. In: EVARISTO, Conceição. Becos da memória. Rio de Janeiro: Pallas, 2017.

FOUCAULT, Michel. Space, knowledge and power. In: RABINOW, Paul. The Foucault Reader. London: Penguin Book, 1984.

FOUCAULT, Michel. De espaços outros. Revista Estudo Avançados, v. 27, n. 79, São Paulo, p. 10-15, 2013.

HALBWACHS, Maurice. A memória coletiva. Trad. de Beatriz Sidou. São Paulo: Centauro, 2006.

LODGE, David. A arte da ficção. Trad. de Guilherme da Silva Braga. Porto Alegre: L\&PM, 2011.

RICOUER, Paul. A memória, a história, o esquecimento. Campinas: Unicamp, 2007.

SAID, Edward. Cultura e imperialismo. Trad. de Denise Bottman. São Paulo: Companhia das Letras, 1995.

SANTOS, Milton. Pensando o espaço do homem. 2. ed. São Paulo: Hucitec, 1986.

SCHMIDT, Simone Pereira. Posfácio: a força das palavras, da memória e da narrativa. In: EVARISTO, Conceição. Becos da memória. Rio de Janeiro: Pallas, 2017. p. 185-190.

Ariane Avila Neto de Farias (arianeaneto@hotmail.com) é doutoranda em Letras, na área de História da Literatura da Universidade Federal de Rio Grande (FURG). Possui graduação em Letras pela Universidade Federal do Pampa (2011) e mestrado em Letras pela Universidade Federal de Pelotas (2017). Atualmente é técnica em educação da Universidade Federal do Pampa. Tem experiência na área de Literatura, Poesia, Gênero, Literatura Brasileira Contemporânea.

Lilian Greice dos Santos Ortiz da Silveira (ortiz.greice@gmail.com) é doutoranda em História da literatura pela Universidade Federal do Rio Grande (FURG) e bolsista Capes. 
Mestra em Literatura Comparada pelo Programa de Pós-Graduação em Letras da Universidade Federal de Pelotas (UFPel). Graduada no curso de Licenciatura em Letras - habilitação em Português-Inglês e respectivas literaturas (2014) pela Universidade Federal de Pelotas (UFPel).

\section{NOTAS DE AUTORIA}

Como citar esse artigo de acordo com as normas da revista

FARIAS, Ariane Avila Neto de; SILVEIRA, Lilian Greice dos Santos Ortiz da. O espaço que somos: as relações entre a favela e a construção da subjetividade em Becos da memória, de Conceição Evaristo. Anuário de Literatura, Florianópolis, v. 24, n. 1, p. 160-172, 2019.

\section{Contribuição de autoria}

Ariane Avila Neto de Farias: concepção, análise de dados, redação e discussão de resultados. Lilian Greice dos Santos Ortiz da Silveira: análise de dados, redação e discussão de resultados.

\section{Financiamento}

O presente trabalho foi realizado com apoio da Coordenação de Aperfeiçoamento de Pessoal de Nível Superior - Brasil (CAPES) - Código de Financiamento 001.

\section{Consentimento de uso de imagem}

Não se aplica.

Aprovação de comitê de ética em pesquisa

Não se aplica.

\section{Licença de uso}

Este artigo está licenciado sob a Licença Creative Commons CC-BY. Com essa licença você pode compartilhar, adaptar, criar para qualquer fim, desde que atribua a autoria da obra.

\section{Histórico}

Recebido em: 20/03/2019

Aprovado em: 14/06/2019

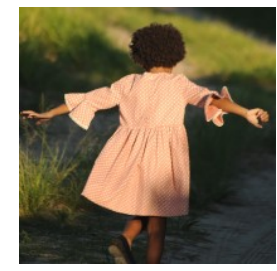

